\title{
Juegos de la Calle: una apuesta transformadora en el territorio escuela-ciudad*
}

\author{
Street Games: a transforming attempt in the school-city environment
}

Jogos de rua: uma aposta transformadora no território escola-cidade

\section{Sandra Maryory Pulido Quintero, ${ }^{\mathrm{a}}$ Juan David Gómez Valenzuela, ${ }^{\mathrm{b}}$ Néstor Guillermo Díaz Jiménez, ${ }^{\mathrm{c}}$ William Moreno Gómez ${ }^{\mathrm{d}}$}

aUniversidad de Antioquia, Medellín (Col.). Integrante grupo de investigación Prácticas Corporales, Sociedad, Educación-Currículo PES. Telf.: (57-4) 2199265. Correo elecrónico: samapuqui@ @otmail.com bUniversidad de Antioquia, Medellín (Col.). Integrante grupo de investigación Prácticas Corporales, Sociedad,

Educación-Currículo PES. Telf.: 57-4) 2199265. Correo electrónico: juangomez.udea@ hotmail.com 'Institución Educativa Antonio Ricaurte y Universidad de Antioquia, Medellín, (Col.). Integrante grupo de investigación Prácticas Corporales, Sociedad, Educación-Currículo PES. Telf.: (57-4) 2199265. Correo electrónico: ngdiazj@gmail.com

dUniversidad de Antioquia, Medellín (Col.). Coordinador grupo de investigación Prácticas Corporales, Sociedad, Educación-Currículo PES. Telf.: (57-4) 2199265. Correo electrónico: williammorenoiuef@gmail.com

\section{RESUMEN}

Se ha dicho que la escuela es un espacio privilegiado para la transformación de la ciudad. Este texto, asociado a la investigación "Documentação, sistematização e interpretação de boas praticas pedagogicas nos processos de educação do corpo na escola", da cuenta del potencial pedagógico con-formador que genera una práctica social educativa que nace en la calle, va a la escuela y de allí, desescolarizada, retorna a la calle, al parque, para favorecer la formación desde una acción lúdica que se reclama transformadora. Esta etnografía descriptiva-comprensiva se orienta por la pregunta ¿Cuál es el potencial curricular de la práctica corporal Juegos de la Calle para la transformación social? Este estudio cultural se desarrolla en una ciudad de 70.000 habitantes que, a fuerza de estar conurbada con Medellín, pasa de su condición semiurbana hacia una condición urbano industrial dependiente.

Palabras clave: escuela, subjetivación, juego, transformación social, foto etnografía.

\begin{abstract}
It has been said that the school is a privileged space for the transformation of the city. This text associated with the investigation "Documentation, systematization and interpretation of good pedagogical practices of education of the body in the school" demonstrates the forming pedagogical potential which generates an educational social practice which being born on the street, goes to the school and afterward returns to the street, park encouraging a changing formation. This comprehensive-descriptive ethnography is guided by the question What is the curricular power of the corporal practice Street Games in the Social Change? This cultural study takes place in a city of 180,000 inhabitants that because of being connected to Medellin changes from semi-urban condition to a dependent urban-industrial.
\end{abstract}

Key words: school, subjectivity, play, social transformation, photo ethnography.

* Este artículo fue solicitado por la Revista Estudios Pedagógicos en diciembre del 2011 en el contexto del proyecto de Investigación FONDECYT (Fondo de Investigación Científica y Tecnológica) No 11110016 , titulado "Educación Física y su función de transformación de las desigualdades sociales: profesorado del área y documentación ministerial”. Además, el articulo se enmarca en el proyecto CICIDEP - Universidad de Antioquia - Colombia "Documentación, sistematización e interpretación de buenas prácticas pedagógicas en los procesos de educación del cuerpo en Caldas - Antioquia". Financiado por INDEPORTES, CNPq y la Universidad de Antioquia. El artículo fue aceptado en junio de 2012. 


\section{RESUMO}

Afirma-se que a escola é espaço privilegiado para a transformação urbana. Associa-se à investigação "Documentação, sistematização e interpretação de boas práticas pedagógicas em educação corporal na escola", informa-se o potencial pedagógico (con)formador que gera uma prática socioeducativa nascida na rua e que chega à escola e, de lá, desescolarizada, retorna à rua, ao parque para favorecer a formação desde uma ação mal interpretada que reivindica para si uma transformação. Esta etnografia descritiva-compreensiva se orienta pela questão: Qual é o potencial curricular da prática corporal de jogos de rua para a transformação social? Desenvolve-se em uma cidade de 180 mil habitantes que, por estar conurbada com Medellín, passa da condição semiurbana à urbano-industrial dependente.

Palavras chave: escola, subjetivação, jogo, transformação social, foto etnografia.

\section{INTRODUCCIÓN}

...no hablo de la ciudad sino de aquello en lo que a través de ella nos hemos convertido. Rainer-María Rilke, Diario Florentino (Martínez Bonafé, 2010).

El interés de este texto pasa por la comprensión del potencial transformador que posee la práctica corporal Juegos Recreativos Tradicionales de la Calle (en adelante JRTC) en la relación escuela-ciudad. Están en debate los límites de la escolarización y todo aquello que allí se curriculariza (Calvo, 2005, 2007; Moreno, 2005; Martínez, 2010) en el caso del juego (Díaz et al., 2011; Galvis, 2009).

Carballeda (2008) plantea que la crisis de los espacios de socialización provoca una serie de cuestionamientos sobre el sentido de esos ámbitos (ciudad, escuela, parque, deporte, juego). Según éste investigador, "esa crisis también da cuenta de un conflicto de los espacios cerrados, en tanto lugares de construcción de subjetividad, de transmisión de pautas, de códigos, de identidades y de pertenencia" (Ibíd.). La escuela, a pesar de que sigue reflejando los efectos de una biopolítica negativa, ${ }^{1}$ es una de las instituciones modernas que mejor ha resistido. Como podemos ver, ella pervive activamente regulando a los individuos a través de la prescripción curricular por medio de imágenes esperadas y previstas para el ejercicio de la integración, la reproducción y el control social. Prácticas conectadas con otros espacios y con otras estrategias y dispositivos de lo social que vehiculizan energía de dominación en la misma dirección es el caso de la fábrica, el club deportivo, la iglesia.

Esta biopolítica negativa podría estarse superando en algunos lugares de la educación (posibilidad de JRTC), ventana ${ }^{2}$ tipo de la micropolítica foucultiana que permitiría disoñar ${ }^{3}$ otra educación, otra escuela, otro juego, otra forma de jugar. Hay una relación entre ética, ${ }^{4}$ vida, resistencia y creación que debe ser revisada si queremos ver el potencial

1 Ver en Rocha (2012) concepto de biopolítica positiva.

2 Desde la teoría de la subjetividad en Foucault se habla de dos formas de constitución del sujeto: una pasiva (sujeción estricta) y otra activa (llevada a cabo por los individuos mismos) a través de prácticas sensatas y voluntarias por las que ellos y ellas no sólo se fijan reglas, sino que buscan transformarse en su ser singular (por autoregulación a través de esa cierta autonomía y ese tal espacio de libertad que le resta); sería el caso del juego desublimado. Para profundizar en el debate ver García (2006: 95).

3 Potencialidad para diseñar nuestros sueños, necesaria desprogramación para comprometerse con un proyecto de vida a la medida de nuestras ilusiones. Ver Calvo (2005) y Nieto (2010).

4 Oscar Henao Mejía (2005) habla de una disidencia ética, puerta que conduce a la autonomía, práctica que 
transformador de dicha práctica corporal de Juegos. Ya llamaba la atención Foucault de que la resistencia “...es proceso de creación. Crear y recrear, transformar la situación, participar activamente en el proceso, eso es resistir" (Lazzarato, 2000). Los pedagogos críticos lo han asumido como "hacer la cosas de otra manera" después de un proceso de confrontación sobre lo que somos, lo que hacemos, cómo lo hacemos y para qué lo hacemos.

La posibilidad de JRTC en los marcos de una biopolítica positiva pasaría por la experiencia comunitaria, investigativa y curricular de diseñar la escuela y los juegos en los marcos de otros compromisos y de otros sentidos en los contextos de una educación en libertad y para la libertad. Esta superación pondría los "juegos vividos" ya no como evento para el consumo, para el sistema, las modas, la repetición, la regulación, sino como territorio para el disfrute, la alegría, el divertimento y el goce, como lugar para la formación, la transformación y la reconstrucción de cultura, de lo social; territorio para el ejercicio de la libertad, lugar para el experimento de una vida digna.

La práctica corporal JRTC surge a mediados de la década del setenta de la mano de tres estudiantes universitarios que, desde la sociología, la medicina y la educación física, ganan motivos para impulsar la práctica del juego tradicional en el Municipio de Caldas; 1981 significa el momento donde se le da sentido como manifestación lúdica universal. Desde la perspectiva de uno de sus iniciadores (Moreno y Betancur, 2008) su valor hoy no está dado por su antigüedad, sino por el valor social que poseen para los afanes políticos, culturales, sociales, corporales del presente. ${ }^{5}$

JRTC constituyen un ritual corporal que tiene momentos preparatorios al interior de la escuela y un momento cúspide donde la escuela y el pueblo se encuentran en la calle $\mathrm{y}$ en el parque. Este rito aparece fuertemente vinculado al cuerpo y, en el caso que nos interesa, a los ejercicios que se hacen sobre lo corporal desde lo social. Esos rituales se manifiestan de múltiples formas en la sociedad contemporánea. Nuestra investigación se interesa por aquellas prácticas ritualizadas que pasan por sensaciones, sentimientos y pasiones relacionadas con la producción de dolor, placer, divertimento, sufrimiento, sentimiento de grupo y re-creación, expresiones que están vinculadas al ejercicio de actividades deportivas, lúdicas y de ocio. Para estos tiempos de desarraigo y conflicto, de fragilidad en los procesos de participación y colaboración social, el juego y la recreación pueden, como parece lo ha demostrado JRTC en Caldas, convertirse en una estrategia de encuentro de los actores y agencias oficiales y no oficiales, formales y no formales, escolares y no escolares, para propiciar procesos de formación y transformación social significativos para los caldeños.

Comprender el proceso de corporización "supone pensar el cuerpo como resultado de un proceso de transformación de la naturaleza que incluye al cuerpo humano que trabaja como parte del proceso de transformación y por lo tanto, como social e históricamente producido" (Milstein y Méndez 1999: 21). De allí que nos interesemos por una práctica, que curricularizada (no solo desde nuestro campo) se despliega "modelativamente" sobre

define sujetos con libertad interior, capaces de pensar, elegir, decidir y responder por sí mismos en el ejercicio de la libertad; ideal supremo, este último, de cualquier modelo de educación.

5 El presbítero Gabriel Jaime Osorio (de la mesa por la paz y la vida) indica que en Caldas (Ant.) se referencian 110 asesinatos en 2009, 80 en 2010 y 60 en 2011 (Radio Caracol, 22 de marzo 2012). Además, después de las 11:00 p.m. no puede haber menores en la calle. 
el cuerpo ¿De qué manera? ¿Cómo? ¿Para qué? ¿Por qué? serán interrogantes que desde esta investigación se abordan.

En el marco de la investigación internacional "Documentação, sistematização e interpretação de boas praticas pedagógicas nos processos de educação do corpo na escola" 6 cinco universidades latinoamericanas desarrollan una investigación situada con relación a las Buenas Prácticas de la Educación del Cuerpo. Para nuestro caso el grupo de investigación Prácticas corporales, Sociedad, Currículo-Educación PES desarrolla el proyecto "Documentación, sistematización e interpretación de buenas prácticas pedagógicas en los procesos de educación del cuerpo en Caldas - Antioquia".

El objeto de conocimiento de nuestro proyecto es el potencial curricular transformador de la práctica corporal JRTC; foco que permite comprender, a través de un estudio etnográfico, los intercambios sensibles que se producen entre los actores y entre los actores y las agencias. En dichos intercambios, la idea es captar los desplazamientos y sus sentidos para una educación transformadora. En términos específicos, nuestro trabajo está orientado por las preguntas: ¿Cuál es el potencial curricular de la práctica corporal Juegos de la Calle para la transformación social? ¿Cuáles son los desplazamientos socioculturales que operan en JRTC? ¿Cuáles sus sentidos?

\section{ALGUNAS PRECISIONES TEÓRICAS Y CONCEPTUALES}

\subsection{LO ESCOLAR}

La preocupación y atención en lo escolar tiene una emergencia de contorno borroso (finales de siglo XVIII, pasando por el siglo XIX y siglo XX, último siglo donde se consolida). Será el proyecto Santanderista de la educación (emergencia de la instrucción pública) el que crea las condiciones definitivas en este país para la constitución de lo escolar. Durante los siglos XVIII y XIX se desarrolla la escolarización tal como hoy la conocemos y con ella la escuela que hoy tenemos. Según Zuluaga (1999: 77), llega así “....a ser la instrucción pública, objeto del saber y del poder". Para ella, la instrucción del pueblo se convierte en un asunto político. Lo escolar se constituye, como texto politizado, en un campo que no trata solamente del conjunto de situaciones de los que se ocupa la educación, se concreta en un práctica que hace parte del paisaje disciplinario que luego se reconfigura en la sociedad de control, de los muros y el encierro a la virtualidad y a las cámaras.

Lo escolar se ofrece como escenario de intervención de otros campos de lo social sobre los implicados (maestros, alumnos, padres, madres, directivas, políticos, funcionarios, comunidad), tiene perímetros planos, dominios, niveles, dispositivos específicos, agentes y discursos. La asunción de lo escolar responde a los intereses de progreso y desarrollo de un Estado que se piensa como mediador de la modernización económica, política, social y moral; constituye un campo de relaciones sociales que define la producción del

6 Participan tres por Brasil, la Universidad Federal de Santa Catarina, la Universidad Federal de Paraná y la Universidad Federal de Río de Janeiro; una por Argentina la Universidad Nacional de la Plata de Argentina y una por Colombia, la Universidad de Antioquia. 
capital curricular y corporal, da o permite identificar el estatuto de legalidad sobre lo que se hace en la escuela; atribuye ese poder.

El sector escolar tiene relación con otros campos. No se reduce a lo judicial, a lo educativo, a lo institucional o a lo económico, contiene espacio, finalidad, personajes, aparatos, tiempo, código, asesores, tutores, autoridades. Es producto de entrecruzamiento de los intereses públicos y privados, religiosos, higiénicos, productivos y reproductivos de orden biológico y social, deportivo, tecnológico y militar. Lo escolar se vehiculiza a través de un complejo de dispositivos normalizadores: la infantilización (Giroux, 2003), la histerización (Varela y Álvarez, 1980) y la heroización, higienización, moralización y deportivización (Moreno, 2009a).

Lo escolar, en su emergencia social, está relacionada con la concreción de una "práctica pedagógica" -ya no una mera "práctica de enseñanza"- en un ambiente y en un contexto politizado y contextuado, es decir, en una economía política del cuerpo.

\subsection{CURRICULARIZACIÓN Y ESCOLARIZACIÓN}

En el entramado de lo social, lo cultural, lo pedagógico y lo curricular (entendido lo curricular como campo profesional, disciplinar e intelectual donde se selecciona y despliega la cultura enseñable), se plantea una problematización crítica que permite un reconocimiento de las implicaciones movilizadoras que, desde el currículo (y al tenor del interés y la tensión social), se dan en el espacio-tiempo de la constitución identitaria, en el territorio del desarrollo educativo y en el campo caótico de las relaciones más abarcantes del poder-saber.

El currículo es un proceso de lo social que pasa a ser experiencia educativa a través de la interactividad de múltiples contextos y paradigmas que interaccionan entre sí. En él, los procesos de curricularización dan cuenta del fin de la escolarización. Desde la curricularización de la cultura, seleccionada para ser enseñada, el poder-saber predica el qué y el para qué de ir a la escuela. Hay una instancia "por fuera de la escuela" que dicta quién va, cómo va y define por qué es importante que la gente transite por la escuela como paso de socialización para hacerse ciudadano, para ser ilustrado o para hacerse productivo, ciudadano-alguien o ciudadano-algo, ciudadano-pleno o ciudadano-siervo.

Tales procesos forman o con-forman a quien por la escuela transita. Gimeno (2005) plantea que "todas esas intenciones han sido formas [curricularizadas] de reproducir seres humanos concebidos como seres deseables [deseados/que deben ser] desde alguna escala de valores [tradicional, culturalista, enciclopédica, técnica, práctica, tradicional, crítica, moderna, postmoderna]". En tal sentido, el acogimiento/internamiento escolar, desarrolla estrategias y tecnologías para la modelación con-formativa o para la formación idealizada del otro, por lo menos en la tradición Griega y occidental, donde para la escolarización no cuenta la libre propensión (Jullien, 2007).

En la educación, desde la tradición platónica se va al desarrollo de los gérmenes interiores del individuo; desde la tradición ambientalista y desde la ilustración, el sujeto se constituye en la estimulación externa (Gimeno, 2005). La escolarización define el proceso de selección de cultura que hacen unos sujetos de poder para adelantar el proceso modelativo de los escolarizados (institucionalizados). La escolarización define una selección intencionada y limitada de cultura; se interesa, no por aquellos conocimientos 
y prácticas que son válidos, sino por aquellos conocimientos y prácticas que, desde algún régimen de verdad, se consideran validos.

La escolarización y sus procesos de curricularización se concentran como capitales que se mueven, que se integran, que se resisten (...); es el caso del capital cultural, simbólico, corporal o curricular seleccionado. El proceso curricularizador lleva una intencionalidad de poder; toda vez que esos capitales son objeto de gestión, control, dosificación, temporización, codificación, encauzamiento y especialización (para ello la escuela se cierra o se abre).

La curricularización finalmente está relacionada íntimamente con los procesos de subjetivación; los sujetos son intervenidos pedagógicamente (subyugación/emancipación) y el currículo, en tanto proceso social encausable, pasa a ser experiencia a través de múltiples sujetos y contextos que interactúan entre sí para intentar dar cuenta (productivamente...) de un tipo de sujeto (deseado socialmente).

\subsection{BUENAS PRÁCTICAS}

Las buenas prácticas definen un campo de la valoración, evaluación, investigación y operación político administrativa de la educación latinoamericana de los últimos tiempos. El discurso oficial coloca en primera línea de conversación el tema de buenas prácticas, significativas (discurso pedagógico) y exitosas (discurso empresarial); generalmente, éstas son direccionadas por las presiones de la política fiscal y curricular nacional e internacional, las que en educación se orienta a través de las políticas de racionalización, buscando identificar buenas prácticas que permitan, ejemplarmente, racionalizar inversión a partir de la réplica ${ }^{7}$ de las experiencias exitosas en diferentes contextos. En otras palabras: se desarrolla una voluntad que desea minimizar los riesgos de la inversión, apoyando el aprendizaje de gestión a partir de algunas experiencias consentidas y resaltadas oficialmente; se trata de un ejercicio inteligente para el buen encauzamiento de los escasos recursos (dixit), invirtiéndolos en experiencias ya probadas. Esta línea de actuación entra en correspondencia con la línea de educación eficaz tan presionada por los agentes de inversión educativa. ${ }^{8}$

Desde la diferencia que podría darse entre una biopolítica positiva y una biopolítica negativa (Rocha, 2009 y 2012; Rodríguez, 2010), podríamos hablar de una Buena "Práctica" como experiencia emblemática de integración-institucionalización o como experiencia emblemática de apertura crítica liberadora. En el primer caso, en su positividad, una experiencia educativa (innovación) que demuestra calidad, eficiencia, eficacia, cobertura y excelencia es colocada como referente para la proyección de la política e inversión del gobierno; o colocada como práctica emblemática que filtrada por una actitud reflexiva y crítica y por los intereses de los más promueve y reproduce subjetividades emancipantes y emancipadoras. Se trata, desde esta segunda opción, de la posibilidad de una reterritorialización educativa que ayudaría a desensimismar la escuela.

7 La política del empresariado organizado en el Consejo Empresarial de América Latina CEAL y del Instituto Latinoamericano de la comunicación educativa, identifica innovaciones educativas que presenten resultados alentadores que preferentemente sean reproducibles (2005: 15).

$8 \quad$ Ver informe de la CEAL, "los empresarios tendrán un marco de análisis e información valida sobre dónde y cómo es más efectivo invertir para apoyar la educación básica, pública o privada” (Ornelas, 2005: 15). 


\subsection{PRÁCTICAS CORPORALES}

La significación de los actos de intervención corporal (a través de las prácticas corporales) parten del presupuesto de pensar estas prácticas como prácticas sociales que tienen sentido y significación en un contexto situado (escolarización). Elaboraciones conceptuales desarrolladas al interior del grupo PES (Universidad de Antioquia) definen las Prácticas Corporales como un conjunto de actividades que componen el arbitrario corporal educativo. A través de ellas podemos develar las estrategias implícitas y explícitas bajo las cuales se cumple un régimen (permitido o prohibido, visible u oculto) de despliegue corporal en la escuela con objetivos intrínsecos u objetivos extrínsecos (se da el caso de prácticas corporales que integran estos dos objetivos).

Las prácticas corporales son complejas ejercitaciones enmarcadas en contextos específicos de la educación física, la educación higiénica, la actividad física y la salud, la recreación, el ocio, el desarrollo comunitario, la participación social y la animación, el desarrollo deportivo o la educación artística. Tales prácticas se valen del compromiso corporal mediado por la lúdica, la recreación, la representación, las maniobras y las disposiciones de control y regulación disciplinaria, todas ellas acciones corporales con niveles normativos y curriculares diferenciados que se caracterizan por un compromiso energético, emocional, político, social y estético diferenciado en la enunciación cotidiana de lo corporal a lo largo y ancho del territorio educativo. Esas acciones se configuran y reconfiguran en función de estrategias pedagógicas; emergen como prácticas de competencia y disciplina, como acciones corporales propias de los ceremoniales -reconocimientos, oraciones, confesiones y reconvenciones-, de los festejos (acrobáticas, carnavalescas, etc.), como disposiciones corporales en las paradas cívicas y religiosas, como prácticas artísticas; como prácticas de limpieza, de presentación, convivencia, cuidado, nutrición, sexualidad, decorado, técnicas o destrezas corporales deportivas, etc. Diríamos que el cuerpo, en su despliegue ritual escolar, es objeto de las Prácticas Pedagógicas Corporales que constituyen el eje por medio del cual el proyecto de la escolarización se hace factible. Desde ellas, se despliega y consolida un estado de subjetivación que se hace posible a través de aquellos dispositivos corporales (feminización, masculinización, patriotismo, religiosidad, etc.) que tales prácticas impulsan (Moreno, 2005 y 2009b).

La intervención pedagógica corporal se da a través de actos comunicacionales (prácticas corporales), por lo tanto, está pautada culturalmente; en ese sentido, el registro de cualquier despliegue, ejercicio o práctica corporal en la escuela, compone un culturema corporal. Sin el rigorismo y el reduccionismo lingüístico, tal culturema constituye una unidad o un complejo de acción corporal (“congelables" para la investigación); ellos, en su significación y simbolización, permiten develar la actitud y la carga energética (en tanto acción social) que habla de la voluntad de poder invertida en el ejercicio escolar con el cuerpo.

\subsection{JRTC Y LA CIUDAD}

JRTC componen una experiencia ludo deportiva situada histórica y socialmente; devienen en un acumulado cultural-corporal que compone lo caldeño, son un producto identitario; son, en sí mismos, un hecho socio-cultural que se relaciona estrechamente con los valores que componen tal cultura de la gente que allí vive, de la gente que allí 
ha jugado los juegos de generación en generación hace más de treinta y un años: ¿desde cuándo, sin ser espectáculo, los jóvenes de Caldas, ya jugaban trompo arriado desde la Tablaza? ${ }^{9}$

JRTC poseen allí, como texto de ciudad, un lugar preponderante; no son una acción deportiva subordinada y emparentada con las actividades municipales de segundo orden. Aparecen como el lugar del deporte y la recreación en las prioridades de gobierno de la ciudad tradicional ${ }^{10}$ y la ciudad moderna. ${ }^{11}$ Los JRTC, históricamente, están emparentados con la ciudad tradicional, la evocan y la traen al presente; los predeportes y, según algunos, eso es JRTC, "eran actividades sociales que no estaban reguladas socialmente, que no estaban sujetas a reglas estrictas, ni estaban arbitradas por instituciones especializadas" (Rodríguez, 2008: 26). Algo propio del juego tradicional es que estaban enclavados en los lugares públicos centrales y simbólicos de villas o aldeas. La sociedad artesanal, diría el investigador citado (Ibíd.), diseñaba los juegos también artesanalmente; cosa que JRTC poseen como una de sus características decisivas. Los predeportes, más relacionados con el juego desublimado, son sometidos a la lógica industrial capitalista, tan interesada en la limitación y en la regulación de fronteras. Ya entrado el siglo XX, son precisos y estandarizados: el deseo perfectible y eficientista llega a la actividad lúdica y se consolidan los premios y las derrotas, los jueces, pugnas, clasificaciones y enmarcaciones, números, tiempos, en definitiva, una economía del cuerpo y una economía del juego.

JRTC estarían más anclados a la ciudad tradicional que a la ciudad moderna; de la ciudad tradicional, el predeporte, el juego; de la ciudad económica (homus economicus, según Racionero, 1998) el deporte reglado. Se impone la ciudad planificada y funcionalista (Rodríguez, 2010: 28). La ciudad tradicional, ciudad laberinto, espacio de la fiesta y de la subversión, ciudad más espiritual que científica, se diferencia con la ciudad moderna en tanto el deporte se integra al plan de ordenación urbana, a la política pública (Barbero, 1993). Ya no es gente que se reúne espontáneamente a jugar; es gente que se reúne a jugar en un espacio-tiempo asignado (monofuncional y monocrónico), en un territorio de gobernanza; juego escolarizado, juego interescolar, juego de representación, juego por premio, por valor, juego reglado. En la ciudad tradicional se hablaba de suelo comunitario, de centralidades religiosa y civil; ahora, en la ciudad moderna, los poderes están descentrados y con ello se rompe la centralidad del espacio; sucede en Medellín y en Caldas que la otrabanda aparece con otras micro-centralidades. Los JRTC en Caldas (ciudad tradicional), difícilmente podrán salir del parque, dado los imaginarios tradicionales que prevalecen en los actores de juegos.

Ellos no aparecen subordinados a otras dimensiones gubernamentales y no gubernamentales de lo social caldeño, y es por ello que no es un asunto que sólo compete al

$9 \quad$ Desde el corregimiento la Tablaza del municipio La Estrella hasta el parque principal del municipio de Caldas. Información de los pioneros de juegos, entrevista a HG 2010/6.3

10 Según Rodríguez (2008: 25), la ciudad tradicional laberíntica y circular, donde lo religioso es lo central, donde el parque de la iglesia mayor es lugar de encuentro, juego, carnaval, mercado, ajusticiamiento, oración y política, suelo comunitario en el que convive lo público y lo privado, lo burgués y lo popular, espacio para todo tipo de funciones sociales. El parque como espacio de ajusticiamiento ha recobrado centralidad en la ciudad intermedia contemporánea colombiana, como muestra la obra de Juan Manuel Echavarría (2010); el espacio deportivo se reconfigura como espacio para el escarnio o espacio para la muerte.

11 La ciudad moderna, definida por Rodríguez (2008: 27), se relaciona con la homogenización del espacio público, donde las normas fijas abarcan el espacio deportivo. 
Instituto de Deporte y Recreación o a la Secretaría de Educación; compete al gobierno todo, a lo social todo, a toda la comunidad, toda ella se moviliza, todos la disfrutan o los padecen. Comparando con lo que significan los juegos indercolegiados ${ }^{12}$ para Medellín, después de asistir en 2010 y 2011 a las diferentes reuniones de JRTC, nos damos cuenta que estos últimos, en Caldas, son un asunto de ciudad, son un asunto del gobierno de la ciudad, ${ }^{13}$ mientras que en la metrópoli los indercolegiados (relativamente comparables con JRTC) son un asunto restringido a educación y deporte a la manera tradicional; en Caldas, el juego ocupa un lugar central en la gestión de la ciudad, si se quiere, un lugar más cercano al ideal juego-polis griego. En la metrópoli el juego es marginal, es de Otrabanda. ${ }^{14}$ Así, JRTC y quienes le juegan, más que un espacio de una tribu rara, extraña a lo social, enclavada en la tradición y en el mito deportivo o recreativo, serían, a la manera de Lefebvre (Cit. en Rodríguez, 2008: 23), un significado en el que se producen relaciones sociales, y el espacio ocupado por juegos, la ciudad, en consonancia con tal tesis, sería un significante que da sentido a las relaciones que allí se cocinan.

Cabe la hipótesis de los JRTC como un desplante sistemático de un pueblo desde hace 31 años, ininterrumpidamente: un paro, un trancón lúdico, un grito; por unos momentos, por unos pocos días, la ciudad jugando se planta y detiene y desvía el tráfico, se apodera de la calle y cierra la vía de la muerte (la vía que le atraviesa puede ser uno de los tramos de mayor accidentalidad ${ }^{15}$ en el país).

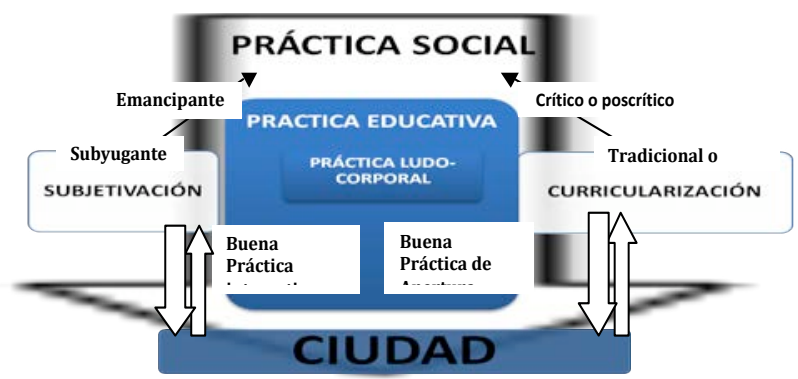

Gráfica 1. Marco referencial para Juegos Recreativos Tradicionales de la Calle

12 Juegos Indercolegiados: organización de los festivales deportivos escolares organizados por Instituto de Deportes y Recreación de Medellín, INDER.

13 Reunión organizadora JRTC: representantes de todas las secretarias de gobierno (Hacienda, Educación, Tránsito, Salud, Gobierno, Deporte...), policía, defensa civil, cajas de compensación, industria y comercio, rectores, mesa de $\mathrm{EF}(\ldots)$.

14 Medellín históricamente esta partida en dos por el río que lleva el nombre de la ciudad. En la margen oriental la ciudad tradicional, en sur oriente la ciudad opulenta, en el nororiente la ciudad empobrecida. Otrabanda la margen occidental se configura en espejo, en el suroccidente clase media y alta y en el noroccidente la ciudad empobrecida. La otrabanda es la ciudad emergente del siglo XX, allí en esa otra ciudad, las galleras, la unidad deportiva, la plaza de toros, el aeropuerto, el parque recreativo Juan Pablo II, el hipódromo San Fernando, los ecoparques; otrabanda, la ciudad del ocio.

15 Una investigación desarrollada por la Universidad de Antioquia aborda 139 registros de personas ingresadas al servicio de urgencias por lesiones producidas por accidentes de tránsito entre 2007-2008. La mayoría de las víctimas fueron hombres entre veinte y cuarenta años de edad. Los usuarios más vulnerables fueron peatones $(33,1 \%)$, seguidos de pasajeros $(30,9 \%)$ y motociclistas $(20,9 \%)$. 


\section{METODOLOGÍA}

Específicamente, este ejercicio de investigación se realiza a partir de un estudio cualitativo etnográfico sobre el juego. Desde la escuela, se interesa por el reconocimiento (descripción/documentación) y la significación comprensiva de aquellas prácticas, técnicas y acciones que componen los JRTC. Se focaliza sobre la condición de contenido curricular con intencionalidad educativa escolarizada, cuestión al parecer inseparable de su concreción como espectáculo social.

En nuestra etnografía (a la manera de Rockwell, 2009), el trabajo de campo está soportado desde la "observación participante"; fue realizado entre 2010 y 2011; el proceso de observación y registro está conectado con los ritmos de los estudiantes y profesores del Instituto de Educación Física que, insertados en la práctica pedagógica universitaria, ya como practicantes, ya como asesores u observadores participantes, desarrollan esta etnografía. El extrañamiento (dado el rol de los participantes), la intersubjetividad (donde la voz de los nativos e investigadores toman lugar) y la descripción densa (expresada en el relato etnográfico), son característicos de este enfoque. Un elemento relevante en nuestro ejercicio investigativo es el privilegio otorgado a la voz de los actores primarios (consideración EMIC, Cfr. Aguirre Batzán, 1995), opción comprensiva que acompaña la narrativa etnográfica.

La fotografía, uso clave en nuestra etnografía, posee un valor descriptivo-comprensivo; acá el grupo de investigación PES ha acumulado una experiencia que nos permite hablar de la "fotoetnografía como medio para etnografiar" (Moreno y Pulido 2008 y 2011; Moreno 2005; Moreno 2009a, 2009b; Moreno y Vanegas 2010; Hincapié, 2011; Vásquez, 2011; Díaz et al. 2011; Mejía 2011, Santa, 2011). El proceso de obturación es guiado por los presupuestos orientadores que acompañan el proceso investigativo. La fotografía no es al azar a no ser que sea el registro libre del sujeto nativo (Luna, 2009).

La foto es una fuente que permite captar el drama cultural/corporal, expresa signos/ símbolos que pueden ser leídos, significados por múltiples actores del proceso investigativo (investigados/investigador). Es un instrumento que se configura en un mediador relacional del contexto, posibilitando descripciones, compresiones y explicaciones más densas. La implicación activa de los fotoetnógrafos es una labor valiosa en tanto su percepción, obturación y lectura es significada por múltiples sujetos participantes de los JRTC, donde el sentido es negociado.

\section{DISCUSIÓN}

En nuestro campo, la reterritorialización de lo antiguo en lo nuevo parece irrefrenable; la desterritorialización de lo tradicional en nuevas formas de proyectar y hacer las cosas deseadas es escasa. Por el contrario, pareciera que, en los escenarios de la educación/ escolarización, se desplegaran en la cotidianeidad, reproduciéndose, irremediablemente, una profunda brecha entre lo deseado y lo logrado. Allí, incluso, lo logrado se parece más a lo tradicional cuestionado que a la educación deseada (ilusión). Irrefrenable, se amplía la diferencia y la distancia entre la retórica modélica tradicional y el drama curricular vivido.

Parece que nada ni nadie pudiera mover la práctica de la educación física o, por lo menos, conmoverla. Pasan los funcionarios, pasan los congresos pedagógicos, las 
capacitaciones de maestros, los pregrados y posgrados, los procesos de transformación y acreditación curricular, la investigación y los macrodiseños de las políticas públicas del campo, los recambios metodológicos modélicos (pedagogía por objetivos, por competencias...), los acuerdos y decretos gubernamentales, las declaraciones gremiales y disciplinares, y es como si no pasara casi nada, como si fuera imposible que los edificios retóricos metafísicos ${ }^{16}$ curriculares de la educación física de nuevo cuño no pudieran concretarse en el drama cotidiano de la intervención pedagógica de los cuerpos.

Basta con recoger las conclusiones de un congreso nacional del campo (2009), que se antoja paradójico en esto de los grandes deseos pertinentes, con escasos resultados en el cotidiano escolar, y valorar hoy, tres años después, el panorama de la clase de Educación Física.

Decían en el Congreso Nacional de Educación Física de 2009, en su marco fílosófico, que el proyecto pedagógico de la Educación Física colombiana debe:

(...) desarrollarse hacia la diversidad, la inclusión y el reconocimiento de las nuevas formas de ser y de asignar sentido a la vida... (que) en el contexto colombiano, la Educación Física debe aportar a la paz, la convivencia y el desarrollo, como ideal y necesidad de todos los sectores sociales, (que) se deben generar proyectos pedagógicos que reconozcan la interculturalidad en la construcción de currículos que reconozcan la identidad de las comunidades y atiendan la diversidad de prácticas de formación de ciudadanía, (que) se deben fortalecer (las) relaciones interinstitucionales e interdisciplinarias para el desarrollo de proyectos conjuntos de Educación Física, Deporte y Recreación orientados hacia el cuidado ambiental, la cultura ciudadana, el rescate de la lúdica y (de) la convivencia social.

La visión mecanicista-instrumental y técnica de prevalencia higiénica y deportivista a pesar de los skills incorporados por la moda mediática, resiste a las posibilidades resignificadoras del campo en los territorios de una escuela que se cree resignificada y reorientada a partir de las reformulaciones teóricas de escasa o nula concreción curricular en el cotidiano educativo.

Hay condiciones estructurales y micro políticas que favorecen la denominada reterritorialización de la educación física tradicional educativa: está la ampliación de cobertura educativa sin profesor de educación física; hablamos del congelamiento de las plazas profesorales y de la falta de estímulos para una cualificación resignificada del profesorado. Se observa que los nombramientos para el área están por debajo de los nombramientos para otras áreas escolares históricamente mejor valoradas que la educación física (Goodson, 1991); también la escasa y tendenciosa cualificación profesoral del campo, para el caso de Antioquia, se traduce en una capacitación técnica instrumentalizada de la pedagogía por competencias (SEDUCA/IUEF 2009-2011, Capacitación por competencias). No escapan los estímulos que realiza la institucionalidad educativa a la investigación técnica o de interés didáctico técnico ${ }^{17}$ de corte competencial. Ya Moreno Doña (2010: 1) observaba una significativa paradoja que vale para Latinoamérica en su conjunto; por un lado, se observa una preocupación retórica por la calidad y equidad educativa, y por el otro, se

\footnotetext{
16 Ver planteamiento de Derrida en Kincheloe, J. (2001) sobre la necesidad deconstruir la retórica curricular metafísica.

17 El premio nacional de Educación Física 2009, patrocinado por COLDEPORTES nacional, se adjudicó una investigación que concreta un modelo competencial para el área de la educación física.
} 
presenta una obsesión curricular instrumentalista y homogeneizadora, visible en la política y la concreción pedagógica de la política de la estandarización.

Nuestra investigación se interesa por una práctica pedagógica corporal que parece asaltar esta lógica y esta continuidad; hablamos de los JRTC caldeños ${ }^{18}$ a lo largo de todo el año, desde hace treinta y un años ininterrumpidamente. Un mes antes de las vacaciones de mitad de año, los juegos se viven intensamente en su fase intramural, municipal y nacional; el resto del año se dedica entre febrero y mayo a su preparación (organización, aprendizaje, entrenamiento, construcción de juguetes y preparación de desfiles) y a la evaluación (agosto a noviembre) y proyección (reflexión sobre la experiencia y creación de condiciones político financieras y pedagógicas para el siguiente evento).

Moviéndose en las márgenes de la escuela, el hogar y la calle -hoy dinamizando y concentrando la actividad escolar, mañana movilizando la dinámica familiar en la construcción del juguete y, luego, impulsando la actividad lúdica callejera de toda la población en la realización del evento ludo recreativo-, los JRTC apuestan por la transformación social.

La crisis de los espacios socializadores tradicionales (escuela, trabajo, familia, esquina, barrio, torneo, campeonato, club) hace que nos cuestionemos el sentido y alcance, el potencial educativo que esos lugares-territorios poseen para la transformación social. Los JRTC se descubren como una práctica emblemática en los procesos de construcción de la subjetividad y la identidad del sujeto caldeño. La desigualdad, la exclusión social, la invisivilización social, la discriminación en los usos del espacio público, la privatización de los espacios de todos, las limitaciones en el acceso a los recursos e infraestructuras públicas, el aislamiento espacial, situaciones concretas de la vivencia en lo social, hacen que nos preguntemos, desde esta investigación, por el potencial curricular transformador de la experiencia educativa "Juegos de la Calle" de Caldas, situación que la presentaría como una Buena Práctica referenciable en los procesos de educación del cuerpo en Colombia.

Los nuevos cimientos de lo social, ligados a la lógica del costo-beneficio, nos muestran un campo social signado por relaciones utilitaristas o por relaciones violentas donde el otro deja de ser constructor de identidad y de confianza y se transforma en un competidor, oponente, enemigo. Debido a ello, se construyen espacios de constitución inefable de la desigualdad y la exclusión social. Para Umpierrez (2002), la formación para la emancipación pasa por el esclarecimiento de cuestiones como estas, cuestiones que constituyen el entramado subjetivo e intersubjetivo con que los actores de la educación (estudiantes y docentes) se abocan a su trabajo (de estudiar y de formar/enseñar), en este caso, a través de una práctica ludo corporal que excede el marco institucional de la escuela, lo desborda impulsándose hacia terrenos más amplios de la educación en sociedad. JRTC favorecen la creación y recreación de una identidad colectiva; el juego se toma la ciudad y, en ese acto, devuelve a los sujetos una visión distinta de sí mismos y de su mundo, una visión recreada histórica, social y culturalmente. El sujeto, jugador, toma elementos y temas de su cultura y de la cultura expuesta y los resignifica. En la perspectiva freiriana se estaría hablando de JRTC como posibilidad de articulación de identidades llevadas lúdicamente hacia la construcción y reconstrucción social y colectiva

18 Participan la iglesia, el comercio, la industria, los padres y madres, las escuelas y universidades, los entes deportivos municipal, departamental y nacional, el profesorado y el alumnado, los rectores, el núcleo educativo y la mesa municipal de educación física, la alcaldía con sus diferentes oficinas (deporte y recreación, educación, hacienda y finanzas, tránsito, salud, comunicaciones, policía), ejército. 
de sentidos de lo social. En JRTC, la educación es educación en autonomía o en heteronomía, educación en libertad o educación enajenadora. JRTC, como estrategia educativa curricularizada, tiene esa doble implicación y, dependiendo del sentido práctico alcanzado, se orienta como espacio de dominación y/o subyugación; como espacio de alienación o como espacio de lucha y transformación.

JRTC presentan una alternativa para la repolitización de las relaciones formativas (ante la despolitización de las instituciones educativas); JRTC permiten la reconstrucción de las relaciones educativas, de las subjetividades e identidades reterritorializadas; en su ludicidad y creatividad social, reterritorializan estableciendo distancia de las consignas centristas de "regresar a lo tradicional", jugar el juego tradicional recreándolo, reincorporándolo sin "sentir localista"; se recrea el vínculo, más que con el juego, con lo jugado.

En esta línea, cabe preguntarse: ¿Qué representa, desde una postura ético política, JRTC para una ciudadanía plena y crítica de los caldeños?

\title{
5. JRTC EN LA FORMACIÓN DEL ESPACIO PÚBLICO. ENTRE LO PRIVADO Y LO PÚBLICO
}

\author{
Ningún individuo se vuelve sujeto sin comenzar por \\ ser subordinado o pasar por un proceso de "subjetivación"... El término "subjetiva \\ ción" comporta en sí mismo la paradoja: designa a la vez el devenir sujeto y el pro \\ ceso de sujeción: no se puede encarnar la figura de la autonomía sino \\ sometiéndose a un poder, sumisión que implica una dependencia radical.
}

Judith Butler

El espacio público es un lugar distinto al espacio íntimo o privado: es el espacio de aparición donde el sujeto se hace visible, cuando aparece en lo político. Según Arendt (2005), la esfera pública está basada en la igualdad y en la universalidad de la ley, y la esfera privada está basada en la particularidad. El concepto de lo público, para Rabotnikoff (2005, Cit. en Casas, 2007), a fuerza de apropiación y de uso (de los más), relaciona la noción con lo estatal, con la parte de todos.

Por su parte, lo público, en la perspectiva de Arendt, significa, según Ramírez (2006), un proceso que une o separa a quienes intervienen en su construcción y como espacio de relación en el que la pluralidad y la diferencia adquieren sentido pleno cuando aparecen articuladas a la búsqueda de lo común como elemento cohesionador. JRTC, como mundo común, se abren como espacio de aparición; los sujetos se agrupan para el juego en el espacio común, en el espacio de todos, en el espacio público. A diferencia de las expresiones del mundo privado, la pluralidad asume el juego como propósito común de los participantes. Para Habermas, la ciudad es espacio público; en éste, el simbolismo colectivo se materializa, expresa la democratización política y social, desde donde se construye la ciudadanía que, para Borrell (2005: 27), es fundamento de la convivencia en democracia. JRTC permitiría la formación de la ciudadanía desde el sujeto de derecho, pero también desde el sujeto ético (formación desde la experiencia, desde el deseo, para el sí mismo). JRTC no son sólo un espacio para entramarse socialmente a través de la comunicación con el otro; son un lugar para la experiencia propia a partir de la vivencia lúdica y creativa del sí mismo, en tal sentido, decimos que posee potencial formador y transformador. En una comprensión de la política, el espacio público es el lugar donde 
el sujeto se expone en el territorio de todos; este espacio se ha ido perdiendo, se ha ido minimizando, se ha difuminado dada la privatización espacial. JRTC amplían el espacio de todos como espacio vivido a través del juego en tanto interés común (La Calle) y emergen ante nuestra mirada como una herramienta pública para "tratar" (si se quiere, a la manera clínica) la desaparición del espacio público en la municipalidad; en un acto de resistencia, JRTC, jugando, contribuyen a modelar el mundo común como un horizonte de entendimiento y encuentro ciudadano.

Martínez (2004) plantea dos matices que deben caracterizar un proyecto que se proponga educar el sujeto y educar la ciudadanía. El primer matiz da cuenta de un espacio que sea producto de una conquista cívica más que de un otorgamiento del Estado; en este caso, JRTC son un espacio que trasciende una condición del debe ser garantizado, respetado, defendido y financiado por el Estado. Son, como se plantea desde el segundo matiz, un espacio que surge de la voluntad del sujeto y que, en el caso de la práctica social, reconfiguran una forma lúdica de vivir la democracia social. El sujeto, jugando, construye el espacio público, pues no hay espacio público sin sujeto.

En JRTC se vive intensa y continuamente el espacio público; en ellos se conoce, se aprende, se gestiona la vida pública y se vive el devenir de lo urbano en la acción misma del juego. En el parque, el juego permite el encuentro del sujeto en tanto individuo y en tanto sujeto social, lugar donde se revalorizan las interacciones sociales en la medida que se estimulan los JRTC como un asunto de todos bajo distintas formas de participación; el espacio público, al decir de Arendt, es "igualdad de desigualdades", un espacio donde quien juega, en la acción de jugar, es sujetado, dominado, subyugado, alienado o liberado; existe allí la posibilidad de emanciparse en y a través de la lúdica.

Para Cardona (2008: 39), "se trata por tanto de valorar el espacio urbano, más que con el criterio de funcionalidad arquitectónica, con el de la vivencialidad y apropiación que éste pueda propiciar a su potencial para ser incorporados de manera sensible por el sujeto...". Para el sujeto emancipable, a la manera de Freire o para la sujetación o la alienación a la manera de los reproduccionistas (Da Silva, 2001), los intereses en el espacio público no son ingenuos, son interesados. Si Martínez (2010) define el currículo [y en este caso se trata de la curricularización de la ciudad por JRTC] como un dispositivo cultural cruzado por relaciones de poder", los JRTC son un dispositivo de subjetivación desde la escolarización o desde el parque.

JRTC se constituye en un espacio legítimo en tanto se constituye en un espacio para el ritual; ritual que expresa formas de autoorganización y socioorganización. En JRTC se manifiesta una forma particular de socialización a través del juego callejero, que llega a operar dispositivos de cohesión social flexible (por medio de la auto y socio regulación) que a través de la escolarización ha fracasado por más que tratan de ludidizarse, como sucede en la fase intramural (Juegos en la escuela). 


\section{FOTOGRAFÍA 1}

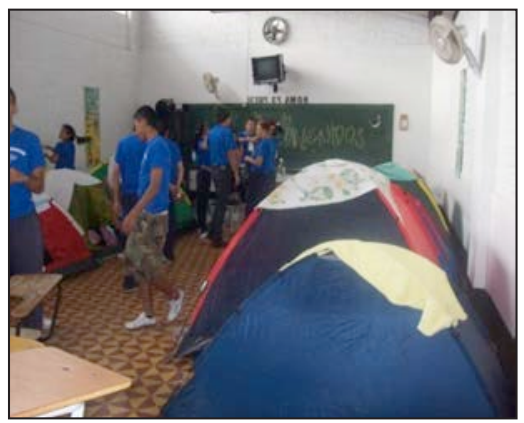

\begin{tabular}{|c|c|c|}
\hline Descripción & $\begin{array}{c}\text { Análisis Las relaciones que } \\
\text { establece el investigador }\end{array}$ & $\begin{array}{l}\text { Categorías } \\
\text { emergentes }\end{array}$ \\
\hline $\begin{array}{c}\text { El aula pertenece a una } \\
\text { institución educativa pública } \\
\text { de Caldas en la que se } \\
\text { observa a unos jugadores } \\
\text { de una delegación que no } \\
\text { son de la ciudad y llegan } \\
\text { en representación de otros } \\
\text { municipios, corregimientos } \\
\text { o veredas; ellos habitan } \\
\text { el salón de clases. Siendo } \\
\text { de distintas delegaciones } \\
\text { interactúan como un todo; } \\
\text { existe un intercambio de } \\
\text { cosas y funciones: tablero, } \\
\text { carteles, sillas, carpas, } \\
\text { toallas, morrales, colchones, } \\
\text { alimentos, higiene, } \\
\text { seguridad. El reloj marca } \\
\text { tiempo de JRTC. }\end{array}$ & $\begin{array}{l}\text { El uso del aula como habitación, } \\
\text { cuarto de hotel o de casa es una } \\
\text { apropiación que se hace sobre } \\
\text { el espacio escolar y responde a } \\
\text { una disposición organizacional } \\
\text { en la que los jugadores de } \\
\text { una delegación son acogidos } \\
\text { familiarmente durante tres o } \\
\text { cuatro días. Se puede observar } \\
\text { cómo se diluye la línea de } \\
\text { lo público en tanto el aula es } \\
\text { habitación; aula en donde los } \\
\text { jugadores comparten sus maneras } \\
\text { de estar en lo privado. Aquí la } \\
\text { forma de dormir, asearse, comer, } \\
\text { se hacen en lo público. Nos } \\
\text { atrevemos a decir que se produce } \\
\text { un desplazamiento se produce } \\
\text { entre lo íntimo, lo privado y lo } \\
\text { público. En JRTC se diluyen las } \\
\text { fronteras entre la matriz escuela } \\
\text { y hogar. Las madres preparan los } \\
\text { alimentos comunitarios en otro } \\
\text { salón, otra aula se transforma en } \\
\text { comedor. }\end{array}$ & $\begin{array}{l}\text { Uso social del } \\
\text { espacio escolar. } \\
\text { Espacio intimo, } \\
\text { privado y público. } \\
\text { Apropiación } \\
\text { espacial. Uso social } \\
\text { de tiempo escolar }\end{array}$ \\
\hline
\end{tabular}




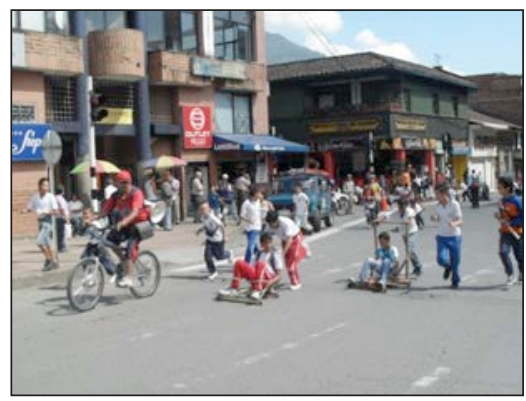

\begin{tabular}{|c|c|c|}
\hline Descripción & $\begin{array}{c}\text { Análisis Las relaciones que } \\
\text { establece el investigador }\end{array}$ & $\begin{array}{l}\text { Categorías } \\
\text { emergentes }\end{array}$ \\
\hline $\begin{array}{l}\text { La escena muestra una } \\
\text { competencia de carros } \\
\text { de rodillos, un grupo de } \\
\text { niños en parejas compiten } \\
\text { empujando sus carros, } \\
\text { ellos con la observación } \\
\text { del profesor juez que va } \\
\text { en bicicleta y orienta con } \\
\text { megáfono. Realizan un } \\
\text { recorrido por las calles que } \\
\text { rodean el parque principal } \\
\text { de Caldas. En la esquina } \\
\text { los agentes de policía y los } \\
\text { guardas de tránsito detienen } \\
\text { el flujo vehicular el cual } \\
\text { es desviado a una calle } \\
\text { secundaria. }\end{array}$ & $\begin{array}{l}\text { Los JRTC como producto de } \\
\text { una conquista cívica (Martínez, } \\
\text { 2004), de las instituciones } \\
\text { públicas (estudiantes y } \\
\text { profesorado) son coorganizados } \\
\text { y financiados por las agencias } \\
\text { del municipio. Los JRTC son } \\
\text { política pública, y así los guardas } \\
\text { de tránsito, la policía nacional, el } \\
\text { instituto de deportes y recreación } \\
\text { de Caldas se coordinan para } \\
\text { que estos niños durante tres } \\
\text { días disfruten de la vía principal } \\
\text { y las vías aledañas al parque } \\
\text { principal sin flujo vehicular } \\
\text { (Juego y resistencia cívica). La } \\
\text { calle es para estos días el espacio } \\
\text { común, es el espacio de todos } \\
\text { y ya no sólo de los carros que } \\
\text { cobran numerosas vidas; allí } \\
\text { se experimenta, se disfruta y se } \\
\text { sufre, no sólo por las laceraciones } \\
\text { producto de las caídas sino } \\
\text { también de la regulación del juez } \\
\text { que no deja pasar la línea de } \\
\text { su bicicleta (la escuela está allí } \\
\text { regulando motricidad). }\end{array}$ & $\begin{array}{l}\text { Apropiación del } \\
\text { espacio público. } \\
\text { El juego acto } \\
\text { de resistencia } \\
\text { cotidiana. } \\
\text { Lo público, la } \\
\text { ciudadanía y la } \\
\text { regulación tempo- } \\
\text { espacial }\end{array}$ \\
\hline
\end{tabular}

Cuadro 1. Ejemplos de análisis fotoetnográfico de JRTC. Acápite sobre uso y apropiación del espacio y el tiempo social en JRTC 
Así mismo, arquitectónicamente, el parque de Caldas deja de ser espacio funcional y se convierte en espacio vivencial a punta de juego. En esta misma dirección, Cardona (Ibíd. 40) encuentra en su investigación que el espacio público contiene “...las infraestructuras urbanas de carácter público: las aceras, calles, parques, plazas, senderos etc., pero también los escenarios de encuentro colectivo y [de] representación social, los espacios de las interrelaciones, las representaciones y las identidades". Ella, apoyada en Signorelli (1999), sostiene que “...se podría decir que, para el arquitecto, la valoración de lo construido se da en términos funcionales; para el usuario, en términos relacionales; si para el primero el espacio construido es el espacio de las funciones, para el segundo es el espacio de las relaciones"; así, para sus jugadores, es una ciudad para otros; es, como lo expresa un comerciante (2010), "un parque al que no hay entrada porque está lleno de gente jugando", un espacio que está dispuesto para jugar.

JRTC suspenden por unos días el flujo privado y privativo del trasporte; integran la formación privada a la formación pública al debilitar, en el juego y con el juego, la frontera escuela pública y esfera privada. Acercan lo privado, lo íntimo (el comercio, la industria, la familia) al espacio de lo público. JRTC ganan inversión (económica, cultural) de todas las agencias estatales municipales alrededor del festival recreativo; abren espacios al homo publicus, al homo ludicus, cerrando el espacio al homo economicus (Racionero, 1998)

En síntesis, la ciudad, para Arendt (Cit. por Martínez, 2010), es el lugar para el encuentro y el reconocimiento del otro, espacio para el encuentro, el juego y el goce sin trabas. JRTC, a fuerza de interés cruzado e intencionado, pedagogizados, se mueven entre lo privado y lo público, entre la escuela y la ciudad, entre la casa y la escuela, entre juego, deporte y educación, entre lo urbano y lo rural, entre lo tradicional y lo posmoderno.

\section{CONCLUSIONES}

JRTC sacan de la vida doméstica a niños y padres, a maestros y estudiantes para recrear una vida en la polis. Existe una desterritorialización de JRTC en su forma organizativa que rompe las lógicas unidimensionales de las secretarías de gobierno; el parque concentra la atención interinstitucional y transinstitucional por encima de las atenciones sectoriales, conjugando acción gubernamental y no gubernamental. JRTC impulsan formas solidarias y cooperativas que modifican la escena social; cambian las formas de interacción y las formas de participación, las formas de ejercicio del poder y la resistencia social. Se expresan por encima de las prácticas unilaterales acciones estratégicas de lo múltiple y lo heterogéneo. JRTC posibilitan relaciones de apropiación, conquista y sometimiento; en ellos se incorpora una multiplicidad de relaciones producidas desde la organización y la participación de las agencias (secretarias municipales, cajas de compensación, comercio, mesa de educación física, iglesia, la escuela) y de los actores (maestro, estudiantes, padres de familia, delegaciones, jueces, artesano de juguetes, coordinadores de juegos, rectores). JRTC son una estrategia de resistencia; al cerrar la calle, se detiene la ciudad motorizada (accidentalidad, movilidad, transporte) y se instaura nuevas formas de uso del espacio de todos; es decir, en el acto de resistir, posibilita otra subjetivación (emancipativa). En 2012, hay voces que claman por sacar JRTC del parque. Las acciones y relaciones estratégicas son producidas porque existe una multitud de fuerzas que actúan desde dentro 
y desde afuera y no sólo en el centro de coordinación de Juegos. Son los gobernantes, los caldeños, los jugadores, los habitantes quienes concretan la participación social como algo que está mas allá de la participación retórica; JRTC muestran que, más allá del sujeto de ley, hay un sujeto ético que juega como duende esperanzador en la política.

\section{REFERENCIAS BIBLIOGRÁFICAS}

Aguirre, A. (1995). Etnografía Metodología cualitativa en la investigación sociocultural. México: Alfaomega Marcombo.

Arendt, H. (2005). La condición humana. Barcelona: Paidós.

Barbero, J.I. (1993). Sociología del deporte. Madrid: La Piqueta.

Borell, M.D. (2005). Hanna Arentd: la política como espacio público. Actas del VII Congreso Español de Ciencia Política y la Administración: Democracia y Buen Gobierno (pp. 23-32).

Butler, J (2001). Mecanismos psíquicos del poder: Teorías sobre la sujeción. Ediciones Cátedra.

Calvo, C. (2007). Del mapa escolar al territorio educativo. Chile: Nueva Mirada Ediciones.

Calvo, C. (2005). Entre la educación corporal caótica y la escolarización corporal ordenada. Revista Iberoamericana de Educación, n.39, 91-106.

Carballeda, A. (2008). Los Cuerpos Fragmentados. La intervención en lo social en los escenarios de la exclusión y el desencanto. Barcelona: Paidós.

Cardona, B. (2008). Espacios de ciudad y estilos de vida El espacio público y sus apropiaciones. Revista Educación física y deporte, n.27-2, 39-47.

Casas, M. (2007). Entre lo público y lo privado un espacio para la convivencia social a través de la comunicación. Razón y Palabra, n.55. Consultado 20 de febrero de 2012, desde www. razonypalabra.org.mx

Da Silva, T. (2001). Espacios de poder. Barcelona: Octaedro.

Díaz, N., Moreno, W., Vásquez, A. y Pulido, S. (2011). Los juegos recreativos tradicionales de la calle; conectando la escuela y la ciudad a través del parque: una etnografía educativa. En J. Suarez (Ed.), Recreación. El parque como encuentro de desarrollo social y ciudadano. Medellín: Funámbulos Editores.

Echavarría, J. (2010). La Guerra que no hemos visto. Exposición en acuarela. Medellín: Suramericana. Obtenido el 3 de marzo de 2012, desde www.laguerraquenohemosvisto.com/ espanol/catalogo_p.1.html

Galvis, N.C. (2009). Prácticas corporales: un despliegue del cuerpo en la tensión de lo formal y lo informal. Revista Educación Física y Deporte, n.28-2, 13-21.

García, M. (2006). Espacio y poder. México: Universidad Autónoma Metropolitana.

Gimeno, M. (2005). La educación que aún es posible. Madrid: Morata.

Giroux, H. (2003). La inocencia robada. Juventud, multinacionales y política cultural. Madrid: Morata.

Goodson, I. (1991). Historia del curriculum. La construcción social de las disciplinas escolares. Barcelona: Pomares-Corredor, S.A.

Henao, O. (2005). La escritura personal como factor potenciador de la educación de los sujetos de la escuela secundaria: experiencia del liceo Benjamín Herrera de Medellín. Tesis doctoral. España: Universidad de Valencia.

Hincapie, A. (2011). La apropiación de las prácticas corporales urbanas de danza en la juventud de Medellín, comuna 13. Conferencia en Expomotricidad 2011. Medellín (Col): Universidad de Antioquia, Instituto de Educación Física.

Jullien, F. (2007). Conferencia sobre la eficacia. Madrid: Katz. 
Kincheloe, J. ( 2001 ). Hacia el pensamiento crítico del pensamiento docente. Barcelona: Editorial Octaedro

Lazzarato, M. (2000). Del biopoder a la biopolítica. Multitudes, n.1

Luna, J. (2009). Foto-etnografía llevada por personas en situación de pobreza en la frontera norte de México. Forum: Cualitative Research, vol.10, n.2

Martínez, J. (2010). La ciudad en el curriculum y el curriculum en la ciudad. En J. Gimeno, (Comp.), Saberes e incertidumbres sobre el curriculum. Madrid: Morata

Martínez, J. (2004). Esfera pública, conocimiento escolar y didáctica crítica. Anuario Conciencia social, n.8, 51-62

Mejía, A. (2011). Sub-Proyecto: Sistematización fotográfica y video gráfica de los juegos recreativos tradicionales de la calle de Caldas Antioquia 2009-2011. Conferencia, Encuentro académico Juegos de la Calle 2011. Universidad LASALLISTA, sede Caldas.

Moreno, W. (2009a). Escuela, cuerpo y milicia, historias de un redoble, de un simulacro que no termina. Educar em Revista, n.33, 93-110.

Moreno, W. (2009b) El cuerpo en la escuela: los dispositivos de la sujetación. Currículo sem Fronteiras, vol.9, n.1, 159-179. http://www.curriculosemfronteiras.org/vol9iss1articles/8moreno.pdf

Moreno, A. (2005). Teoría del caos y educación informal. Huelva: Hergué.

Moreno, W. (2005). Un desfijador de significado para la intervención de lo corporal en el medio escolar. RIE (Organización de Estados Iberoamericanos), n.39 Septiembre-Diciembre. http:// www.rieoei.org/rie39a07.pdf

Moreno,W. \& Betancur, G. (2008). Los Juegos de la Calle, un reflejo de los limites de la escolarización, un horizonte para la formación en el libre juego. Educación Física y Deporte, Vol.1, n. 27, 23-27.

Moreno, W \& Pulido, S (2008). Documentación, sistematización e interpretación de las buenas prácticas pedagógicas en los procesos de educación del cuerpo. Para Colombia en el proyecto PROSUL, Programa Sul-Americano de Apoio às Atividades de Cooperação em Ciência e Tecnologia. Edital CNPq Chamada II - Projetos Conjuntos em C\&T\&I coordinado por Alexander Fernández Vas.

Moreno, W \& Pulido, S (2011). El paseo escolar en los contextos de la educación tradicional, objetiva y activa: aporte para la comprensión del pulso de la pedagogía moderna en el campo de la naciente educación física. En V. De Melo y M. Taborda, Sport, Educacao Physica e Modernidade: Um panorama da America do sul (pp.74-99). Río de Janeiro: Brasil.

Moreno, W. \& Vanegas, S. (2010). Aproximaciones históricas al modo de ser deseado para la mujer en la Medellín de finales del siglo XIX y principios del Siglo XX. Conferencia en la Universidad Nacional de la Plata. Argentina: Universidad Nacional de la Plata.

Milstein, D. \& Mendes, H. (1999). La escuela en el cuerpo. Madrid: Miño y Dávila Editores

Nieto, D. (2010). Educación artística. Disoñar la escuela "para sembrar y cultivar un jardín de infantes planetarios". Congreso Iberoamericano de Educaciòn, Metas 2021. Buenos Aires.

Ornelas, C. (2005). Buenas prácticas de educación básica en América Latina (Informe). CEAL/ILCE (Consejo Empresario de América Latina y del Instituto Latinoamericano de la Comunicación Educativa). http://www.ceal-int.org/educa/TomoI.pdf

Rockwell, E. (2009). La experiencia etnográfica. Historia y cultura en los procesos educativos. Buenos Aires: Paidós

Racionero, L. (1998). Del paro al ocio. Barcelona: Editorial Plaza

Ramírez, P. (2006). La fragilidad del espacio público en la ciudad segregada. Ponencia para el seminario "Pobreza, desigualdad y exclusión en la sociedad del siglo XIX. Un debate conceptual-metodológico IIS-UNAM”. Septiembre 27 y 28

Rodríguez, R. (2010). Notas para una investigación sobre pedagogía y Biopolítica. Educación física y deporte, vol. 29, n.2. 
Rocha, L. (2012). Educación Física para una Biopolítica positiva. En línea http://unlp.academia.edu/ lilianarocha/Papers/1345717/Educacion_Fisica_y_curriculum._para_una_biopolitica_positiva. Consulta 18 de febrero de 2012.

Rocha, L. (2009). Educación Física... La fuerza del dispositivo biopolítico en la educación del cuerpo. Pensar la Práctica. Vol. 12, n.2

Rodríguez, A. (2008). El deporte en la construcción del espacio social. Madrid: EFCA, S.A.

Santa, M. (2012). Espacio escolar y tribus urbanas: el caso de la Institución Educativa San José Obrero en el corregimiento San Antonio de Prado. Educación física y deportem Vol. 31, No. 1.

Signorelli, A. (1999). Antropología urbana. Barcelona: Anthopos.

Umpierrez, A. (2002). Aportes de la comunicación institucional para transformar la escuela. Conferencia en VI Congreso Latinoamericano de ciencias de la comunicación. Bolivia: Santa Cruz de la Sierra.

Varela, J y Álvarez, F. (1980). De la histerización del cuerpo de la mujer. Viejo Topo, n.42, 8-14.

Vásquez, A. (2011). Representaciones sociales del estudiantado y profesorado de Caldas (Antioquia) sobre los juegos recreativos tradicionales de la Calle. Maestría en Motricidad y Desarrollo Humano. Conferencia en Expomotricidad 2011. Medellín (Col.): Universidad de Antioquia, Instituto de Educación Física.

Zuluaga, O. (1999). Pedagogía e historia. Medellín: Editorial Universidad de Antioquia. 